\title{
Action of Morphine on the Epinephrine Output and the Blood Sugar Content in Dogs, Anaesthetized with Avertin.
}

\author{
By \\ Hiroshi Sato, Tune. Degti and Yas. Satow. \\ (佐 藤 熙) (出口恒三郎) (佐藤 保雄) \\ (From the Physiological Laboratory of Prof. Y. Satake, \\ Tohoku Imperial University, Sendai.)
}

This investigation is an extension of the previous research which dealt with the influence of avertin narcosis upon the accelerating property of insulin on the output rate of epinephrine. ${ }^{1)}$

All the techniques and procedures here utilized should be understood as being wholly the same as those written there. Only here morphine was administered instead of insulin. Morphine was dosed as 10 mgrms. per kilo and injected under the skin and Dog 1 in our previous experiments on morphine ${ }^{2)}$ was taken as the control.

Exp. 1. Dog, weighing 11.1 kilos, was first clysterized with glycerin-water, then with 11 c.c. avertin. 5 minutes afterwards the dog staggered, reflexes were abolished; 15 minutes later the lumbar route operation began. About one hour after the end of the operation the first blood samples were taken from the suprarenal vein, and $10 \mathrm{mi}-$ nutes later again. They were finally found indicating a rate of $0.00001 \mathrm{mgrm}$. per kilo per minute. The blood sugar content was measured as $0.072 \%$ and $0.073 \%$. Then morphine hydrochloride solution was given in the dose and manner, above related. The narcosis became profound, the blood dark. And the epinephrine secretion rate was measured as only doubled for two hours, but 2.5 hours after the morphine injection it was measured as about tripled the initial rate, and 0.5 hour later it had quadrupled. The increase was solely

1) Sato, Satow and Degti, Tohoku J. of Exp. Med., 1934, 24, 495.

2) S a to and $0 \mathrm{hmi}$, Ibid., 1933, 21, 411 . A missprint there (Dog 1 on p. 428) must be corrected : the IX. blood sample contained $0.14 \%$ sugar instead of $0.41 \%$. 


\section{TABLE.}

The epinephrine output, blood sugar content, etc. in avertin-anaesthetized dogs, after subcutaneous injection of morphine.

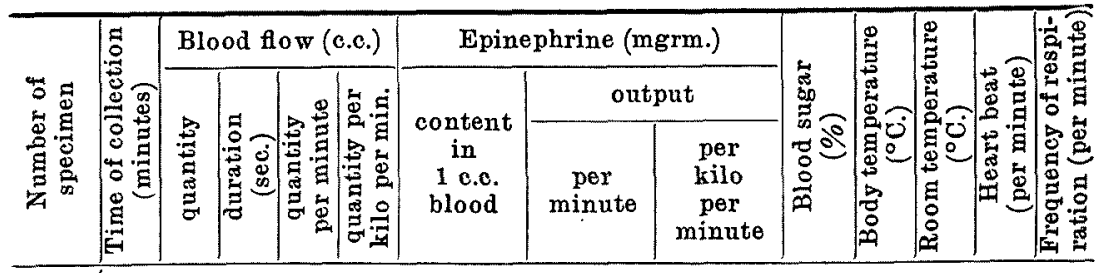

Exp. 1. 11.1 kilos $\delta$. 13. IX. 1933.

9:05 a.m. Clyster with glycerin (20 c.c.) and water (20 c.c.).

9:20 " 11 c.c. of avertin administered.

9:25 Staggered and reflexes decreased.

9:40-10:30 Deep anaesthesia and left lumbar route preparation.

11:20 Anaesthesia very deep, then experimented on as follows:befor

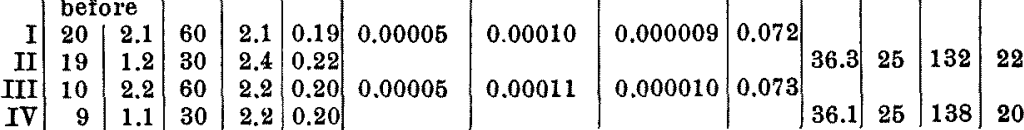

11:40 a.m. 5.5 c.c. of $2 \%$ morphine solution injected subcutaneously in 6 second (10 mgrms. per kilo).

\begin{tabular}{|c|c|c|c|c|c|c|c|c|c|c|c|c|c|}
\hline & \multirow{2}{*}{\multicolumn{2}{|c|}{ fter }} & & & & & & & & & & & \\
\hline $\mathbf{v}$ & & & & & & & & מחת & & & & & \\
\hline VI & 31 & 1 & 30 & 28 & 0.25 & & & & & 5 & 26 & 46 & \\
\hline VII & 6 & 1. & 60 & 1.9 & 0.17 & 0.00010 & 0.00019 & 0.000017 & 0.102 & & & & \\
\hline III & 61 & 1.0 & 30 & 2.0 & 0.18 & & & & & .2 & 27 & 172 & \\
\hline IX & 90 & 1.9 & 60 & 1.9 & 0.17 & 0.00010 & 0.00019 & 0.000017 & 0.110 & & & & \\
\hline $\mathbf{X}$ & 9 & 1. & 30 & 2.0 & 0.18 & & & & & .1 & 27 & 168 & \\
\hline$X I$ & 120 & 2.1 & 60 & 2.1 & 0.19 & 0.00010 & 0.00021 & 0.000019 & 0.121 & & & & \\
\hline XII & 18 & 1. & 30 & 2.2 & 0.20 & & & & & 35.1 & 26.5 & 168 & \\
\hline III & 15 & 1.9 & 60 & 1.9 & 0.17 & 0.00020 & 0 & & .134 & & & & \\
\hline$x T y$ & 10 & 1. & 30 & 2,2 & 0. & & & & & 35.1 & 27 & 164 & \\
\hline $\mathrm{x}$ & 180 & 1.9 & 60 & 1.9 & 0.17 & 0.00025 & 0.00047 & 0.000042 & 0.139 & & & & \\
\hline $\mathrm{x}$ & & & 30 & & & & & & & & 27 & 44 & \\
\hline
\end{tabular}

3:0 p.m. Shed about 80 c.c. blood from r. fem. artery.

6:20 The wound sewed up.

Anaesthesia deep and smooth. Colour of specimens. V.-XII. very dark.

Exp. 2. 9.0 kilos $0.27 .1 \mathrm{X} .1933$.

9:20 a.m. Clyster with glycerin (20 c.c.) and water $(20$ c.c.).

9:23 " Defecation.

9:51-10:10 Administered 300 c.c. of $2.5 \%$ "Avertin-fest" solution.

10:20-11:05 Left lumbar route preparation.

11:50 Experimented on as follows under deep anaesthesia.

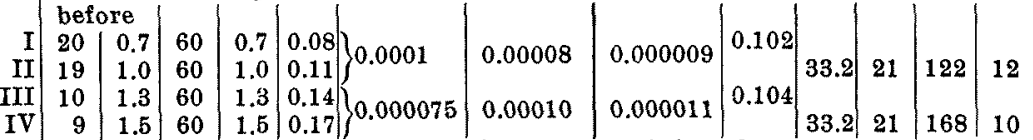

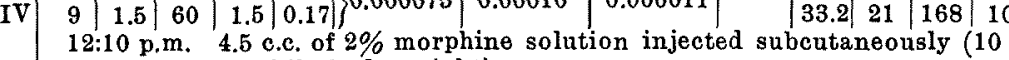
mgrms, per kilo body weight).

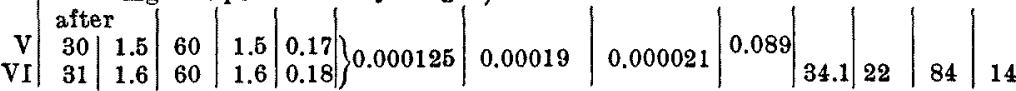




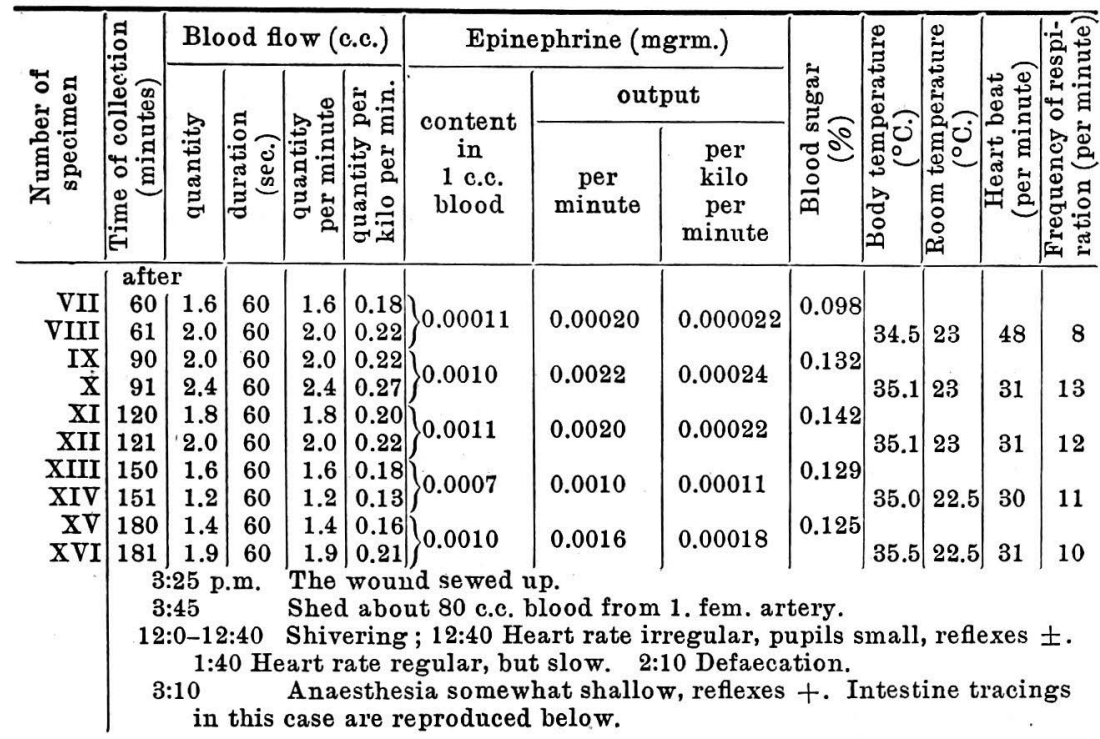

Intestine tracings for Exp. 2.

(Reduced to $\frac{2}{3}$ )

In all the intestine tracings, at the mark " $x$ " atropine-T y rode's solution, in which the rabbit intestine segment was beating rhythmically, was replaced by indifferent blood solution, and at the "numeral" the indifferent blood solution to which a certain quantity of adrenalin chloride of Sankyo Co. was added, or by the blood specimen solution. All the blood solutions were prepared by diluting with 4 volumes of Tyrode's solution, and the quantity of the blood employed for one assay was 0.5 c.c.

The numeral of specimens and the quantity of adrenaline solution which is showed in c.c. and in concentration were added to each observation. For example, " $0.11 / 2000 "$ shows " 0.1 c.c. of adrenaline solution with the concentration of $1 / 2000 \mathrm{mgrm}$. in 1 c.o." i.e. $0.00006 \mathrm{mgrm}$. adrenaline. To show the I specimen, we used the numeral "I"

In all tracings, time intervals are 30 seconds.

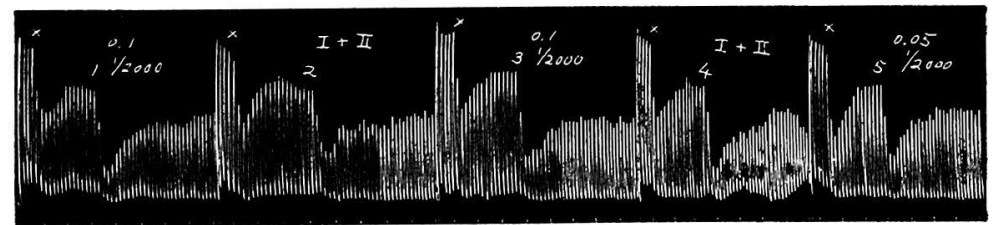

Fig. a. I+II: Almost as strong as $0.00005 \mathrm{mgrm}$., and a little stronger than $0.000025 \mathrm{mgrm}$. 


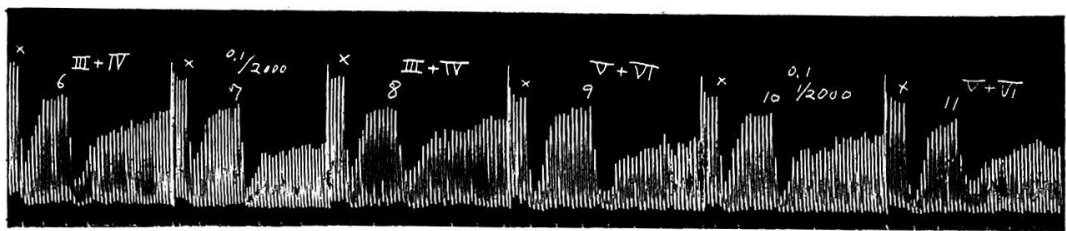

Fig. b. III+IV: Stronger than $0.000025 \mathrm{mgrm}$. but weaker than $0.00005 \mathrm{mgrm}$. V+VI: Stronger than (III+IV) and $0.00005 \mathrm{mgrm}$.

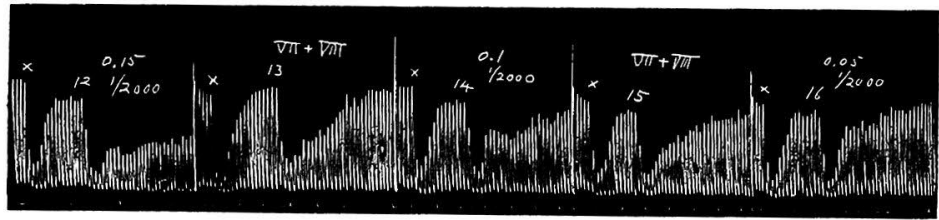

Fig. c. V+VI: Weaker than 0.000075 mgrm. VII+VIII: Weaker than 0.000075 mgrm., a very little stronger than $0.00005 \mathrm{mgrm}$. and stronger than $0.000025 \mathrm{mgrm}$.

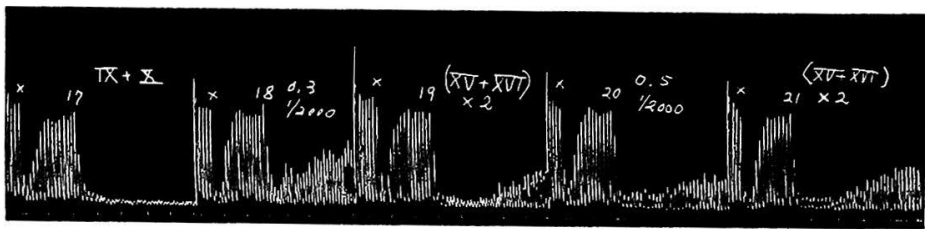

Fig. d. IX+X: Far stronger than $0.000025 \mathrm{mgrm}$. and $0.00015 \mathrm{mgrm} . \quad(\mathrm{XV}+\mathrm{XVI})$ $\times 2$ : Stronger than $0.00015 \mathrm{mgrm}$. and almost as strong as $0.00025 \mathrm{mgrm}$.

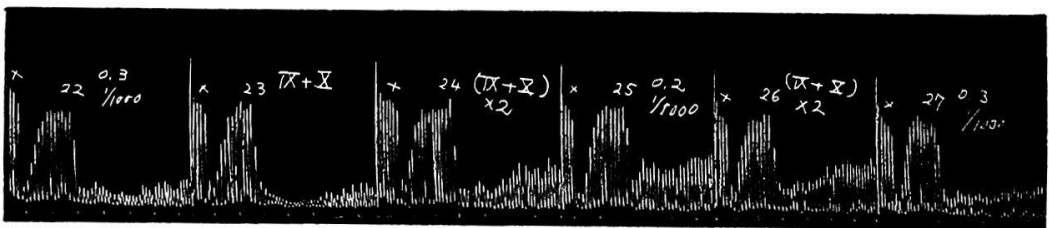

Fig. e. $(\mathrm{XV}+\mathrm{XVI}) \times 2$ : Weaker than $0.0003 \mathrm{mgrm}$. $\mathrm{IX}+\mathrm{X}$ : Stronger than 0.0003 mgrm. (IX+X) $\times 2$ : Stronger than $0.0002 \mathrm{mgrm}$., but weaker than $0.0003 \mathrm{mgrm}$.

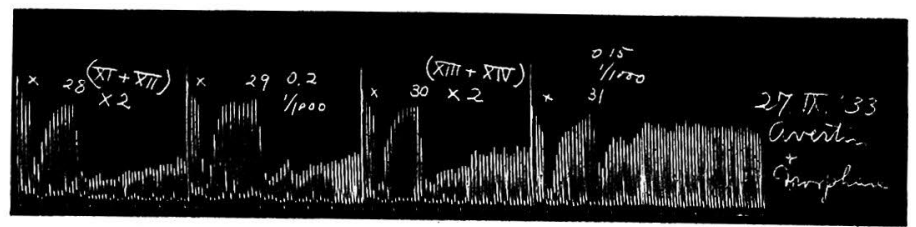

Fig. f. $\quad(\mathrm{XI}+\mathrm{XII}) \times 2$ : Almost as strong as or a very little weaker than $0.0003 \mathrm{mgrm}$. and stronger than $0.0002 \mathrm{mgrm}$. (XIII+XIV) $\times 2$ : Weaker than $0.0002 \mathrm{mgrm}$, and stronger than $0.00015 \mathrm{mgrm}$. decidedly. 
To sum up:-

I+II: Almost as strong as $0.00005 \mathrm{mgrm}$, and a little stronger than $0.000025 \mathrm{mgrm}$. It was assayed at $0.0001 \mathrm{mgrm}$. per 1 c.c. III+IV : Stronger than $0.000025 \mathrm{mgrm}$. but weaker than $0.00005 \mathrm{mgrm}$. It was taken as $0.000075 \mathrm{mgrm}$. per 1 c.c. V+VI: Stronger than (III+IV) $(0.0000375 \mathrm{mgrm}$.) and $0.00005 \mathrm{mgrm}$. Weaker thân $0.000075 \mathrm{mgrm}$. It was assayed at $0.000125 \mathrm{mgrm}$. in 1 c.c. VII + VIII: Weaker than $0.000075 \mathrm{mgrm}$., a very little stronger than $0.00005 \mathrm{mgrm}$. and stronger than $0.000025 \mathrm{mgrm}$. It was taken as $0.0001 \mathrm{mgrm}$. per 1 c.c. or $0.000125 \mathrm{mgrm}$. in 1 c.c. i.e. $0.00011 \mathrm{mgrm}$. IX +X: Far stronger than $0.000025 \mathrm{mgrm}$. and $0.00015 \mathrm{mgrm}$. Stronger than $0.0003 \mathrm{mgrm}$. (IX $+\mathrm{X}$ ) $\times 2$ : Stronger than $0.0002 \mathrm{mgrm}$, but weaker than $0.0003 \mathrm{mgrm}$. It was taken as 0.0010 mgrm. per 1 c.c. $\mathrm{XI}+\mathrm{XII}$ : $(\mathrm{XI}+\mathrm{XII}) \times 2$; Almost as strong as or a very little weaker than $0.0003 \mathrm{mgrm}$. and stronger than $0.0002 \mathrm{mgrm}$. It was taken as $0.0012-\mathrm{mgrm}$. or $0.0010^{+}$mgrm. per 1 c.c. i.e. $0.0011 \mathrm{mgrm}$. in 1 c.e. XIII $+\mathrm{XIV}$ : $(\mathrm{XIII}+\mathrm{XIV}) \times 2$; Weaker than $0.0002 \mathrm{mgrm}$, and stronger than $0.00015 \mathrm{mgrm}$. decidedly. It was taken as $0.0007 \mathrm{mgrm}$. in 1 c.c. $\mathrm{XV}+\mathrm{XVI}$ : $(\mathrm{XV}+\mathrm{XVI}) \times 2$; Stronger than $0.00015 \mathrm{mgrm}$. and almost as strong as $0.00025 \mathrm{mgrm}$. Weaker than $0.0003 \mathrm{mgrm}$. It was taken as 0.0010 mgrm. in 1 c.c.

due to the change of the concentration of epinephrine in the suprarenal vein blood; the blood flow through the gland remained unchanged.

The blood sugar content increased slowly too, so that $0.14 \%$ was estimated at the end of three hours of the morphine intoxication. The body temperature decreased also. The nutrition of this dog was not good, the body temperature was low from the beginning of the experiment. The pulse was increased a little by morphine.

Exp. 2. After glycerin-enema 2.5\% "Avertin-fest" solution was given per recti; 300 c.c. were found sufficient for causing somewhat deep anaesthesia. The epinephrine output rate was $0.00001 \mathrm{mgrm}$. per kilo per minute before morphine, but under avertin, and the blood sugar $0.1 \%$, the pulse rate about 170 a minute. $2 \%$ morphine solution was given under the skin in a dose of $10 \mathrm{mgrms}$. per kilo. The animal awakened a little, stretched, and the reflexes were positive; but later the animal became more quiet as if asleep, but the reflexes were never abolished. For one hour after morphine the rate of epinephrine secretion was measured as only a little increased, but half an hour later a rate as great as twenty times the initial, namely 0.00024 mgrm. per kilo per minute, was measured, and after another half an hour it was still about the same, but then the rate began to decrease, though slowly. This increase is solely or chiefly due to an increase of the epinephrine content of the suprarenal vein blood. The blood sugar which showed at one time a tendency to decrease, was estimated as increasing hand in hand with the secretion rate of the epinephrine, the maximum being noted as $0.142 \%$ two hours after the morphine injection. The morphine pulse became manifest. 
In spite of the co-existence of avertin anaesthesia the morphine was capable of eliciting an accelerating secretion of epinephrine from the suprarenal gland of dogs and also an increase of the blood sugar concentration. In one out of two experiments the maximum rate of epinephrine secretion was of a wholly similar degree, to that previously detected in the normal dog receiving the same amount of the drug, and in the remaining it was far small. The degree of hyperglycaemia was of about the same magnitude in these three dogs. Only the latency, with which the hyperepinephrinaemia and hyperglycaemia became manifest, is clearly retarded in the dogs under avertin.

Thus it may be said with definiteness that morphine is capable of eliciting an exaggeration in the epinephrine output rate and in the blood sugar content even when applied to dogs under the influence of avertin. 